\title{
Fertility will be determined by the changing ideal family size and the empowerment to reach these targets
}

\author{
Wolfgang Lutz, ${ }^{1, *}$
}

\section{Introduction}

The long-term fertility trends in different parts of the world will matter greatly for sustainable development and future human well-being on this planet. Progress in the global demographic transition and the resulting changes in the sizes and structures of human populations have been shown to be key drivers of modern economic growth through several mechanisms. Unified Growth Theory (Galor 2011) clearly demonstrates how the increase in human capital associated with the shift from the quantity to the quality of children has been driving economic development. This has also been shown by the extensive literature on the demographic dividend (Bloom and Williamson 1998; Lutz et al. 2019). But the future paths of fertility and the resulting population growth have also been identified as important factors in efforts to deal with climate change and other environmental risks (Bongaarts and O'Neill 2018). The effect of fertility on economic growth and environmental change may be even more important than the challenges posed by population growth in providing people with the ability to live a life of dignity and freedom from poverty, as stipulated by the Sustainable Development Goals (SDGs). It is clearly harder to meet all of these goals while leaving no one behind - one of the key SDG principles - if the world population continues to grow rapidly. Among the Shared Socioeconomic Pathways (SSP), the Stalled Development Scenario (SSP3) projects that the global population will grow to around 14 billion people by the end of the century, while the Rapid Development Scenario (SSP1) projects a corresponding figure of just seven billion (Lutz et al. 2018). This difference by a factor of two,

\footnotetext{
${ }^{1}$ Department of Demography, University of Vienna, International Institute for Applied Systems Analysis (IIASA), Vienna Institute of Demography (VID), Austrian Academy of Sciences, Wittgenstein Centre for Demography and Global Human Captial (IIASA, OeAW, University of Vienna), Vienna, Austria *Correspondence to: Wolfgang Lutz, lutz@iiasa.ac.at
} 
which is mostly due to different fertility assumptions, will have serious implications for future human well-being.

Where future population growth will come to lie between these two rather extreme scenarios will essentially depend on two factors: the speed of fertility decline in Africa and the long-term fertility level at the end of demographic transition. In this contribution to the demographic debate, I will argue that for both factors, changes in the ideal family size - which I will use here synonymously with the desired family size - are the key drivers. Moreover, I will show that these changes primarily happen in our minds, and are only secondarily influenced by changing economic realities and environmental factors. Another reason why I prefer to use the notion of the ideal family size is that it is directly linked to the notion of developmental idealism, which has been discussed extensively with respect to family norms by Arland Thornton (2005). This approach is based on the premise that our actions are a consequence of our norms, and of what we consider as good and desirable in our minds. But before we can realize these desires, we need to be empowered to do so. This empowerment has several dimensions, which go from women being able to convince their partners - and, in some societies, their extended family and peers as well - to allow them to pursue their family size desires, to having access to acceptable means of contraception and reproductive health services (including medically assisted reproduction). As I will argue below, for many of the dimensions of this process of reproductive empowerment, female education is a decisive factor.

\section{The future of Africa's fertility}

Much has been written about the drivers of fertility decline in Africa, and I will not attempt to summarize this literature here. I only aim to selectively highlight a few recent insights into this complex topic. In the 2010 issue of the Vienna Yearbook of Population Research on the topic of education and demography, John Bongaarts published a paper entitled "The causes of educational differences in fertility in SubSaharan Africa" (Bongaarts 2010), in which he clearly showed that the main reason for the high fertility in Africa is that the desired family size is large. More educated women have both a smaller desired family size and fewer unwanted births. Hence, education has a dual effect on lowering fertility: i.e., it reduces the ideal family size, presumably through changes in values and in the associated quantity/quality considerations; and it empowers women to actually realize this smaller family size by averting unwanted births.

This pattern of explanation has recently been confirmed by two highly comprehensive studies (Kebede 2019; Kebede et al. 2019) that pooled all the individuallevel data from all African countries and for all years that are available from the DHS (Demographic and Health Survey), which enabled the authors to study more than 1.8 million births to more than 500,000 women. One interesting finding from a multi-level study of differentials in the ideal family size (Kebede 2019) was that at each level (individual, community, and country) the effect of education was stronger 
than that of income, and that the effect of education was particularly strong at the community level. This implies that even less educated women who were living in a village with more educated women had smaller ideal family sizes, presumably due to processes of normative diffusion and social learning (Kebede 2019). A cohortspecific analysis of fertility showed that the much-discussed stalling of the fertility decline around 2000 in some African countries can be largely explained by an earlier stalling of improvements in education - possibly in association with the structural adjustment programs of the 1980s - among the female cohorts who entered their prime childbearing ages around 2000 (Kebede et al. 2019). Here again it was apparent that more educated women wanted to have fewer children, and were finding better ways to actually have fewer children. And given that the education of girls has picked up again in many African countries since 2000, a rather rapid decline in fertility over the coming years seems likely.

\section{Fertility levels at the end of demographic transition}

In Africa and in some countries in Western Asia where fertility is still rather high, the factors that will lead to fertility decline are relatively clear, and the only open question is the exact timing of this decline. By contrast, the main drivers of and the long-term trends in fertility are much more uncertain in populations that have reached the end of the demographic transition. Here we are groping in the dark, and only feel confident in saying that the long-held view that all countries will ultimately converge to the so-called replacement level of 2.1 is untenable, and without a scientific basis. This perspective appears to reflect some sort of belief in homeostasis that assumes that there is an inherent tendency of populations to reach a state of equilibrium in which they neither grow nor decline. This view has also been reinforced by the ubiquity of the United Nations population projections. For decades, these projections had assumed that life expectancy would stabilize at a certain level, which had to be shifted upward repeatedly as reality surpassed previous estimates; and that fertility in all countries would converge to the replacement level, and thus reach a point of permanent stability after a period of some turmoil caused by the demographic regime changes associated with the demographic transition. This view was also politically convenient for the United Nations, because it told governments that conditions would stabilize: i.e., that their populations would neither explode nor shrink and ultimately disappear. Unfortunately, reality has turned out to be different, as today an increasing number of governments - mostly in Eastern Europe - are deeply concerned about depopulation, not only due to low fertility, but to outmigration.

In global population projections, the long-term fertility target has now been lowered from 2.1 to somewhere between 1.75 and 1.85 (United Nations 2019; Lutz et al. 2014). However, there is no convincing scientific rationale for these estimates. Hence, one may ask why such long-term projections are even produced. The problem is that long-term population projections are needed for many purposes - 
e.g., the study of climate change and the human populations affected in different parts of the world - and that in making such projections, one must assume some TFRs over the long term, even if the scientific basis for doing so is very tenuous. Gietel-Basten et al. (2013) have presented some sensitivity analyses of the very longterm implications of different ultimate fertility levels. In the scenarios that assume a maximum life expectancy at birth of 100 years, and that the stated fertility levels will be reached in all parts of the world by 2050, a long-term TFR of 1.75 would result in a world population of 8.5 billion in $2100,5.6$ billion in 2200 , and 3.2 billion in 2300 . If the TFRs converge to 2.0 by 2050 , the long-term population size would be in the 10-11 billion range over the coming centuries. If, however, the TFRs converge to 1.5 - which is around the current European average - the world population would, after peaking at 8.6 billion, decline to 6.9 billion by 2100 , and further decline to 2.7 billion in 2200 and 0.9 billion in 2300. In other words, the current European levels, which are still higher than the levels currently observed in East Asia, would, in the very long run, bring the world population down to below one billion - that is, to the level that humanity experienced throughout its entire history up until around 1800 .

These purely hypothetical scenario calculations show that minor differences in fertility levels can have massive consequences for long-term population size. And my point here is that the question of whether a TFR is 1.50 rather than 1.75 or 2.00 will primarily depend on the ideal that is in people's minds as to what number of children is associated with living a successful and happy life.

\section{Revisiting the low fertility trap hypothesis (LFTH)}

In 2006, Lutz, Skirbekk, and Testa published a paper in the Vienna Yearbook of Population Research that was entitled "The low fertility trap hypothesis: Forces that may lead to further postponement and fewer births in Europe" (Lutz et al. 2006). The underlying concept was based on the following hierarchy for fertility and births. First, personal ideal family size is assumed to be the fundamental driver of fertility, which is then transformed into a specific family size target when conflicting interests and constraints are taken into account. In a next step, these fertility targets are translated into period fertility rates that are sensitive to choices around the timing of births. Finally, period fertility rates are translated into certain absolute numbers of births in a given calendar year for which the changing age structure of the population is also taken into consideration. At each of these steps, external influences come into play that partly represent feedbacks from earlier fertility levels, as is evident in the case of the age structure of the population and the number of young people entering reproductive ages. But the key hypothesis of LFTH is that the most basic underlying determinant - namely, personal ideal family size - is in part determined by how young people have been socialized, and by what they see as the new norms pursued by other people around them. These experiences shape young people's own norms about family size. This can also be seen as feedback from earlier declines in fertility that resulted in smaller actual family sizes, and which, in turn, influenced 
the family size norms of the next generation. This mechanism by itself could result in a downward spiral of ever-lower fertility and ever-smaller actual family sizes, even if no other factors come into play.

In 2008 in a paper discussing LFTH in Europe and East Asia, I asked the question: "Has Korea's fertility reached the bottom?" (Lutz 2008). At that time, the TFR in South Korea was 1.25, and few people believed it could fall any lower. In 2018 and 2019, the Korean TFR has actually fallen below 1.0. While this very low period fertility level is likely due in part to tempo effects that are a consequence of the postponement of births, to what extent fertility in South Korea will recover over the coming years is not at all clear. Following the LFTH framework, this very low level could also be due to changes in either the ideal family size, important competing aspirations and conflicts that result in lower target fertility, or a combination of the two. There is not yet enough empirical evidence to disentangle these different determinants of fertility in East Asia. But in the urban areas of China, there is some evidence that after many years of living under the one-child policy, and in a situation in which most couples actually have only one child, the one-child family has become the new norm, with a large majority of couples saying that they want to have only one child, even though they are now allowed to have two (Basten and Jiang 2015).

In Europe, by contrast, the two-child norm still seems to be dominant, at least until recently (Sobotka and Beaujouan 2014). Over the last decade, a rather unexpected decline in fertility rates has been observed in several European countries, including in the Nordic countries. This pattern in the Nordic countries is particularly puzzling given that these countries used to be seen as the prime examples for the premise that ensuring the compatibility of work and family and having generous child support systems will result in relatively high fertility levels. In Norway, for example, the TFR has declined from 1.96 in 2008 to 1.56 in 2018. In Finland, the TFR has declined from 1.85 to 1.40 over the same period, without any clearly identifiable social, economic, or family policy changes having occurred. Demography is still groping in the dark for explanations for these changes. It appears, however, that there may well have been some ongoing cultural changes in these societies that have affected the relative importance of children, and, as a consequence, the ideal family size.

\section{Empowered to better reach one's ideal family size}

In an earlier Demographic Debate in the 2017 Vienna Yearbook on education and fertility in low-fertility settings, I gave my contribution the title: "Education empowers women to reach their personal fertility target, regardless of what that target is" (Lutz 2017). In this paper, I also explained some of the mechanisms through which the cognitive learning experiences associated with education tend to strengthen abstraction skills, lengthen the planning horizon, and even improve self-control. These benefits are in addition to the more widely recognized effects of education, which include having better access to information and the ability to 
earn a higher income. These are all key aspects of the empowerment of women, which, among many other good things, improve their chances of realizing whatever their family size ideals are. I have discussed this contribution of female education to fertility decline in Africa above. But this empowerment effect is also present in many low-fertility countries. It can help explain why in some countries a U-shape emerges in the relationship between education and fertility. Assume for the time being that the ideal family size is two children for all women, irrespective of education. In such a scenario, women with low education will tend to have relatively high levels of fertility, because there is still a degree of fatalism in their reproductive behavior, and higher proportions of their births are likely to be unplanned. On the other extreme, women with high education will tend to be able to plan their life more effectively, even if they often have to deal with difficult trade-offs between advancing their career and establishing a family. But they will also tend to have higher levels of human and social capital that will enable them to better combine work and family life, and, therefore, to come closer to their ideal of having two children than women with intermediate income levels, who are likely to struggle more to make ends meet, and to combine work and family life in a satisfactory manner. Thus, this latter group of women are likely to have somewhat lower fertility. Hence, these differences in the empowerment of women can help to explain the emerging U-shape in several countries.

I still believe that this narrative is plausible and probably right. But in that case, why don't we observe a U-shape with respect to education in all low-fertility countries? The reason is that not all women in a given country have the same ideal family size, and they are even less likely to have identical family size targets. Empirically observed fertility differentials tend to result from a mixture of the ideal family size and empowerment effects. While I still believe that the empowerment effect is universal in all cultures and at different levels of the fertility transition, the ideal family size can differ considerably. For example, highly educated orthodox Jewish women in Israel often want very large families, and manage to have very large families. But in other countries, large proportions of highly educated women have evidently accepted that having children is not compatible with having a career, and manage these trade-offs by staying childless. Thus, in the long run, culturally and socially determined family size desires may result in very different fertility levels.

Is there something in our genes that will ensure that a certain minimal level of fertility is maintained? From a purely biological perspective, the sex drive seems to be the main mechanism that evolution produced for ensuring that there will be sufficient reproduction. This is also reflected in Robert Malthus' famous statement that fertility is unlikely to decline because "the passion between the sexes will never diminish" (Malthus 1798). But thanks to contraception, fertility around the world has declined without the passion having diminished. Reproduction has now mostly entered the realm of conscious choice (Coale 1973). And where will this conscious choice lead us? I got the clearest answer to all of these crucial questions from the leading evolutionary biologist Simon Levin of Princeton. In response to 
my question of whether human evolution will ensure a certain minimum level of reproduction, his short answer was: "Once reproduction is culturally determined, cultural evolution can bring you almost anywhere." And the key mechanism through which culture works in this context is via the shaping of the ideal family size as the fundamental determinant of future fertility.

\section{References}

Basten, S. and Q. Jiang 2015. Fertility in China: An uncertain future. Population Studies 69(sup1): S97-S105. https://doi.org/10.1080/00324728.2014.982898.

Bloom, D. E. and J. G. Williamson 1998. Demographic transitions and economic miracles in emerging Asia. The World Bank Economic Review 12(3): 419-455. https://doi.org/10. 1093/wber/12.3.419

Bongaarts, J. 2010. The causes of educational differences in fertility in Sub-Saharan Africa. Vienna Yearbook of Population Research 8: 31-50. https://doi.org/10.1553/ populationyearbook2010s31

Bongaarts, J. and B. C. O’Neill 2018. Global warming policy: Is population left out in the cold? Science 361(6403): 650-52. https://doi.org/10.1126/science.aat8680.

Coale, A. J. 1973. The demographic transition. In International population conference, edited by IUSSP, 1:53-72. Liege, Belgium: International Union for the Scientific Study of Population.

Galor, O. 2011. Unified growth theory. Princeton: Princeton University Press.

Gietel-Basten, S., W. Lutz and S. Scherbov 2013. Very long range global population scenarios to 2300 and the implications of sustained low fertility. Demographic Research 28(39): 1145-1166. https://doi.org/10.4054/DemRes.2013.28.39.

Kebede, E. 2019. The relative importance of female education on fertility desires in Sub-Saharan Africa: A multi-level analysis. VID working paper 09/2019. Vienna, Austria: Vienna Institute of Demography of the Austrian Academy of Sciences. https://www.oeaw.ac.at/fileadmin/subsites/Institute/VID/PDF/Publications/ Working_Papers/WP2019_09.pdf.

Kebede, E., A. Goujon and W. Lutz 2019. Stalls in Africa's fertility decline partly result from disruptions in female education. Proceedings of the National Academy of Sciences 116(8): 2891-2896. https://doi.org/10.1073/pnas.1717288116.

Lutz, W. 2008. Has Korea's fertility reached the bottom? The hypothesis of a 'low fertility trap' in parts of Europe and East Asia. Asian Population Studies 4(1): 1-4. https://doi.org/ $10.1080 / 17441730801963110$.

Lutz, W. 2017. Education empowers women to reach their personal fertility target, regardless of what the target is. Vienna Yearbook of Population Research 15: 27-31. https://doi.org/ 10.1553/populationyearbook2017s027

Lutz, W., W. P. Butz and S. KC (eds) 2014. World population and human capital in the twenty-first century. Oxford, UK: Oxford University Press. http://ukcatalogue.oup.com/ product/9780198703167.do. 
Lutz, W., J. C. Cuaresma, E. Kebede, A. Prskawetz, W. C. Sanderson and E. Striessnig 2019. Education rather than age structure brings demographic dividend. Proceedings of the National Academy of Sciences 116(26): 12798-12803. https://doi.org/10.1073/pnas. 1820362116.

Lutz, W., A. Goujon, S. KC, M. Stonawski and N. Stilianakis 2018. Demographic and human capital scenarios for the 21st century: 2018 assessment for 201 countries. Luxembourg: Publications Office of the European Union. https://doi.org/10.2760/41776.

Lutz, W., V. Skirbekk and M. R. Testa 2006. The low-fertility trap hypothesis: Forces that may lead to further postponement and fewer births in Europe. Vienna Yearbook of Population Research 4: 167-192. https://doi.org/10.1553/populationyearbook2006s167

Malthus, T. R. 1798. An essay on the principle of population. London: J. Johnson.

Sobotka, T. and É. Beaujouan 2014. Two is best? The persistence of a two-child family ideal in Europe. Population and Development Review 40(3): 391-419.

Thornton, A. 2005. Reading history sideways: The fallacy and enduring impact of the developmental paradigm on family life. 1st edition. Chicago: University of Chicago Press.

United Nations. 2019. World population prospects: The 2019 revision. New York, NY: Department of economic and social affairs, population division. http://esa.un.org/unpd/ wpp/.

Open Access This article is published under the terms of the Creative Commons Attribution 4.0 International License (https://creativecommons.org/licenses/by/4.0/) that allows the sharing, use and adaptation in any medium, provided that the user gives appropriate credit, provides a link to the license, and indicates if changes were made. 